\title{
The Effect of Incorporation of Cellulose Kenaf Fibers in Composite Resin on Mechanical Properties and Surface Topography Analysis Using Scanning Electron Microscopy
}

\author{
Nur Aliya Ibrahim ${ }^{1}$ Rabihah Alawi ${ }^{2}$ Yanti Johari ${ }^{3} \quad$ Nor Aidaniza Abdul Muttlib ${ }^{3}$ \\ Mohd Nazrulhuzaimi Md Yusoff ${ }^{3}$
}

${ }^{1}$ Klinik Kesihatan Batu Gajah, Ministry of Health, Kelantan, Malaysia

${ }^{2}$ Conservative Unit, School of Dental Sciences, Universiti Sains Malaysia, Kampus Kesihatan, Kota Bharu, Kelantan, Malaysia

3 Prosthodontics Unit, School of Dental Sciences, Universiti Sains Malaysia, Kampus Kesihatan, Kota Bharu, Kelantan, Malaysia

${ }^{4}$ Dental Biomaterial Unit, School of Dental Sciences, Universiti Sains Malaysia, Kampus Kesihatan, Kota Bharu, Kelantan, Malaysia

Eur J Gen Dent 2021;10:7-13.
Address for correspondence Rabihah Alawi, BDS, MDSc, Conservative Unit, School of Dental Sciences, Universiti Sains Malaysia, Kampus Kesihatan, 16150 Kubang Kerian, Kota Bharu, Kelantan, Malaysia (e-mail: rabihah@usm.my).

\section{Abstract \\ Keywords \\ - kenaf fibers \\ - fiber-reinforced composite \\ - flexural strength \\ - compressive strength}

Objective This study aimed to evaluate the flexural and compressive strength of kenaf-reinforced composite resin as well as analyze the length and diameter of kenaf fibers and their surface topography.

Materials and Methods Kenaf fibers were alkaline treated and wetted with coupling agent. Kenaf-reinforced composite resin was fabricated manually. Specimens for kenaf-reinforced composite resin (Tetric N Flow [Ivoclar Vivadent, Liechtenstein] $+2 \%$ kenaf) and control group (Tetric N Flow [Ivoclar Vivadent, Liechtenstein]) were prepared using stainless steel molds with dimension of $25 \mathrm{~mm} \times 2 \mathrm{~mm} \times 2 \mathrm{~mm}$ and $6 \mathrm{~mm} \times 4 \mathrm{~mm}$ for flexural and compressive strength tests, respectively, and tested using Instron Universal Testing Machine (Shimadzu, Japan). Raw kenaf fibers, treated kenaf fibers, and fractured sample from flexural strength test were analyzed using scanning electron microscopy (SEM) (FEI Quanta FEG 450, United States). Data were analyzed using independent sample $t$-test. Significant level was set at $p<0.05$.

Results Kenaf-reinforced composite resin has a lower flexural and compressive strength than the control group $(p<0.05)$. SEM analysis revealed the average fibers' length to be $1.24 \mathrm{~mm}$ and diameter ranging from 6.56 to $12.9 \mu \mathrm{m}$. The fibers dispersed in composite as single strand or a bundle with a minimal gap between fibers and composite.

Conclusion Flexural and compressive strengths of kenaf-reinforced composite resin were lower than the control group, despite some adaptation between kenaf fibers and composite noted. The fibers' length and diameter were reasonable for the dispersion in the resin matrix; however, additional treatments of kenaf are required for a favorable result.
DOI https://doi.org/ $10.1055 / \mathrm{s}-0041-1732918$ ISSN 2320-4753
(C) 2021. European Journal of General Dentistry.

This is an open access article published by Thieme under the terms of the Creative Commons Attribution-NonDerivative-NonCommercial-License, permitting copying and reproduction so long as the original work is given appropriate credit. Contents may not be used for commercial purposes, or adapted, remixed, transformed or built upon. (https://creativecommons.org/licenses/by-nc-nd/4.0/). Thieme Medical and Scientific Publishers Pvt. Ltd. A-12, 2nd Floor, Sector 2, Noida-201301 UP, India 
Key Messages: Up to this date, there have been no dental composite resins that use natural fibers as filler, which will produce fiber-reinforced composite resin that is cheaper and will be less harmful to the environment and health. Modifications on the kenaf fibers surface treatment is required to increase fiber-matrix adhesion, thus increasing the mechanical properties.

\section{Introduction}

Composite resin is commonly used in dentistry for esthetic repair and replacement of dental tissue. The mechanical properties of composite resin are being continuously improved due to its high demand and application. Filler is one of the composite resin components that has been modified most since composite resin was first introduced. ${ }^{1}$ Several methods have been attempted to improve the mechanical properties of resin composites such as by using discontinuous S2-glass fibers. ${ }^{2}$

Nowadays, the use of natural fibers as filler in composite has gained a lot of interest because these fibers are low in tool wear and density, cheaper, readily availability, nontoxic, and biodegradable as compared with the synthetic fibers. ${ }^{3-6}$ One of the natural fibers is kenaf fiber which has been incorporated to reinforce the polymer matrix composite. ${ }^{7}$ Kenaf fiber exhibited favorable mechanical properties to be reinforced in polymer composite and can be used as an alternative to glass fiber. ${ }^{6-8}$

Kenaf plant is the plant from Hibiscus cannabinus species, where it is grouped into Hibiscus genus and its family is Malvacea. This plant was found to be an important source of fiber for composites and other industrial application. ${ }^{6,9}$ It is mainly found in subtropical and tropical part of Africa and Asia. Major constituent of fiber is cellulose embedded in hemicellulose and lignin. ${ }^{7}$ Cellulose is known to have excellent mechanical properties depending on the fiber's length, loading, aspect ratio, orientation, and interfacial adhesion with matrix. ${ }^{10}$

There are some disadvantages of kenaf fiber, one of them is the hydrophilic properties of cellulose that affect the interphase bonding between fiber and hydrophobic polymer as a matrix. ${ }^{9}$ In addition, exposure of the fibers to the atmosphere or aqueous media can cause long-term failure due to water absorption into the fibers. Thus, surface modification of kenaf has been done to improve the characteristic of the fibers such as alkaline treatment (mercerization) to remove lignin, hemicellulose, wax, and oil that cover the surface of the fibers. ${ }^{7}$ Fibers need to be immersed in sodium hydroxide $(\mathrm{NaOH})$ solution to increase surface roughness for better mechanical interlocking and help in increasing the number of exposed celluloses on fiber for more sites of reaction. ${ }^{8}$ Alkaline treatment also provides a lasting effect on strength and stiffness of the fibers. ${ }^{9}$

Other component of composite resin is silane coupling agent. The alkoxyl end of the silane coupling agent binds to the filler surface and the vinyl end undergoes addition reaction with resin matrix. This substance helps to enhance mechanical properties and provides a water-resistant bond at interphase of filler and matrix resins producing a durable composite for clinical application. ${ }^{1}$

Various modifications were done on composite resin such as reinforcement of the composite resin with synthetic glass fiber to improve its properties. However, based on the authors' knowledge, up to this date, there is no composite resin that uses natural fibers as filler. Reinforcement of composite with natural fibers will produce composite with cheaper cost, excellent mechanical properties, as well as less harmful to the environment and health. Therefore, in this study, we assessed the suitability of using kenaf fiber to improve mechanical properties of composite resin. The flexural and compressive strength of composite resin were evaluated after incorporation of cellulose kenaf fiber. The average length and diameter of kenaf fibers, the surface topography of raw kenaf fibers, treated kenaf fibers, and fractured surface of kenaf-reinforced composite resin were assessed using scanning electron microscopy (SEM).

\section{Materials and Methods}

\section{Ethical Clearance}

This study did not require ethical approval as no human or animal subjects were involved.

\section{Materials}

Materials used in this study are as shown in - Table $\mathbf{1}$.

\section{Preparation of Cellulose Kenaf Fiber}

Preparation of the cellulose kenaf fiber was performed according to Kargarzadeh et al. ${ }^{11}$ Kenaf fiber was obtained from Lembaga Kenaf dan Tembakau Negara, Kota Bharu, Kelantan, Malaysia.

\section{Alkaline Treatment of the Kenaf Fibers \\ Prior to the alkaline treatment, kenaf fibers were first man- ually cut into $3-\mathrm{mm}$ length as preliminary fiber's length and later were treated with $4 \mathrm{wt} \% \mathrm{NaOH}$ solution at $80^{\circ} \mathrm{C}$ for 3 hours under mechanical stirring. Alkaline treatment was repeated thrice. Filtration using filter paper and washing}

Table 1 Materials used in this study

\begin{tabular}{|l|l|l|l|l|}
\hline \multirow{2}{*}{ No. } & \multirow{2}{*}{ Raw material } & \multicolumn{2}{|c|}{ Composition } & \multirow{2}{*}{ Manufacturer } \\
\cline { 3 - 4 } & & Resin matrix & Inorganic filler & \\
\hline 1 & $\begin{array}{l}\text { Tetric N flow composite } \\
\text { resin }\end{array}$ & $\begin{array}{l}\text { Bis-GMA } \\
\text { TEDGMA }\end{array}$ & $\begin{array}{l}\text { 63.8\% barium glass, ytterbium trifluoride, } \\
\text { mixed oxide, silicon dioxide }\end{array}$ & Ivoclar Vivadent, Liechtenstein \\
\hline 2 & Kenaf fiber & - & - & - \\
\hline
\end{tabular}

Abbreviations: Bis-GMA, bisphenol A-glycidyl methacrylate; TEDGMA, triethylene glycol dimethacrylate. 
using distilled water were performed in between each treatment to remove the alkali-soluble component.

\section{Bleaching Treatment of the Kenaf Fibers}

The residual lignin was removed by subsequent bleaching treatment. Equal parts of acetate buffer (solution of $2.7 \mathrm{~g}$ $\mathrm{NaOH}$ and $7.5 \mathrm{~mL}$ of glacial acetic acid in $100 \mathrm{~mL}$ of distilled water), aqueous chlorite $(1.7 \% \mathrm{w} / \mathrm{v})$, and distilled water were used as solution to perform this treatment at $80^{\circ} \mathrm{C}$ for 4 hours under mechanical stirring. This step was also repeated thrice. After the bleaching treatment, fibers were filtered using filter paper, distilled water was used to wash the fibers, and then the fibers were air dried.

\section{Acid Hydrolysis Treatment of the Bleached Fibers}

The bleached fibers were treated with acid hydrolysis which was conducted at $45^{\circ} \mathrm{C}$ under mechanical stirring using $65 \mathrm{wt} \% \mathrm{H}_{2} \mathrm{SO}_{4}$ (preheated). After the treatment was completed, the cold distilled water was added to dilute the suspension which then stopped the reaction.

\section{Preparation of Composite Incorporated with Kenaf Fibers}

The treated kenaf fibers were completely wetted with silane coupling agent, 3-methacryloxypropyltrimethoxysilane, and stored at room temperature for 24 hours. The fibers were then manually incorporated into the composite resin, Tetric N Flow (Ivoclar Vivadent, Liechtenstein). All components were initially weighed using analytical balance (HR-200, A\&D Company Limited, Japan) and then mixed.

\section{Testing for Mechanical Properties}

Two groups of specimens were prepared which consisted of kenaf fiber-reinforced composite resin (Tetric N Flow [Ivoclar Vivadent, Liechtenstein] $+2 \%$ kenaf fiber) and Tetric N Flow composite resin (Ivoclar Vivadent, Liechtenstein) (control). The percentage of kenaf fiber (2\%) was decided as preliminary experimental fiber content. The specimens were prepared for flexural and compressive strength tests as summarized in - Table 2 .

\section{Flexural Strength Test}

Ten specimens of each group of material were prepared according to ISO 4049/2000 specifications in $25 \mathrm{~mm} \times 2 \mathrm{~mm}$ $\times 2 \mathrm{~mm}$ dimension using stainless steel mold. The mold was filled with composite resins (experimental and control restorative material) with a glass lid placed over the mold and light cured for 40 seconds using LED light curing unit
(Elipar Freelight 2, 3M ESPE, Germany). The digital caliper (Mitutoyo, Japan) was used to measure the specimens' thickness and height. All specimens were stored in distilled water at $37^{\circ} \mathrm{C}$ for 24 hours. The flexural strength test was then performed using Instron Universal Testing Machine (Shimadzu, Japan) at a crosshead speed of $0.75 \mathrm{~mm} / \mathrm{min}$, with $5 \mathrm{kN}$ loading force.

\section{Compressive Strength Test}

Ten cylindrical specimens of each material were prepared using stainless steel mold with internal dimensions of $4 \mathrm{~mm}$ diameter by $6 \mathrm{~mm}$ height. The mold was filled with (experimental and control restorative material) and a glass lid was placed over the mold and light cured for 40 seconds using LED light curing unit (Elipar Freelight 2, 3M ESPE). The specimens' thickness and height were both measured using a digital caliper (Mitutoyo) before testing. The specimens were stored in distilled water at $37^{\circ} \mathrm{C}$ for 24 hours. The compressive strength test was later performed using an Instron Universal Testing Machine at a crosshead speed of $0.75 \mathrm{~mm} / \mathrm{min}$, with $5 \mathrm{kN}$ loading force.

\section{Scanning Electron Microscopy Analysis}

The analysis was performed using SEM (FEI Quanta FEG 450, United States) on the raw kenaf fibers and treated kenaf fibers to measure the average length and diameter of the fibers and on a randomly selected fractured sample of kenaf-reinforced composite resin from flexural strength test to analyze surface topography. The samples were first fixed on a metal stub and sputtered with gold (one cycle of 120 seconds) under vacuum, using a sputtering device.

\section{Statistical Analysis}

Statistical analysis was performed using SPSS software (IBM SPSS Statistics version 24, Chicago, United States) and the results were then analyzed using independent sample $t$-test.

A $p$-value of less than 0.05 was considered as statistically significant.

\section{Results}

\section{Flexural and Compressive Strength}

There was a significant difference in flexural and compressive strength between the two composites whereby Tetric N Flow (Ivoclar Vivadent, Liechtenstein) composite resin portrayed a higher flexural and compressive strength as compared with the kenaf-reinforced composite resin. Comparison of mean flexural and compressive strength between kenaf-reinforced

Table 2 Experimental and control groups

\begin{tabular}{|l|l|l|l|l|l|}
\hline \multirow{2}{*}{ Dental composite } & \multirow{2}{*}{$n$} & \multicolumn{2}{|c|}{ Tests } & \multirow{2}{*}{ Kenaf fiber (wt\%) } & Composite resin (wt\%) \\
\cline { 3 - 4 } & & FS & CS & & 98 \\
\hline $\begin{array}{l}\text { Kenaf fiber-reinforced composite resin } \\
\text { (Tetric N Flow composite resin + kenaf fiber) }\end{array}$ & 10 & $1 \mathrm{~A}$ & $1 \mathrm{~B}$ & 2 & 100 \\
\hline Tetric N Flow composite resin & 10 & 2A & 2B & 0 & 100 \\
\hline
\end{tabular}

Abbreviations: CS, compressive strength; FS, flexural strength. 
Table 3 Comparison of mean flexural and compressive strength (MPa) between kenaf-reinforced composite resin and Tetric N Flow composite

\begin{tabular}{|c|c|c|c|c|c|c|}
\hline \multirow[t]{2}{*}{ Tests } & \multirow[t]{2}{*}{$n$} & $\begin{array}{l}\text { Kenaf-reinforced } \\
\text { composite }\end{array}$ & Tetric N Flow & $\begin{array}{l}\text { Mean difference } \\
(95 \% \mathrm{Cl})\end{array}$ & \multirow[t]{2}{*}{$\begin{array}{l}t \text { statistic } \\
\text { (df) }\end{array}$} & \multirow[t]{2}{*}{$p$ - value ${ }^{a}$} \\
\hline & & \multicolumn{2}{|c|}{ Mean (MPa) (SD) } & & & \\
\hline Flexural strength & 10 & $\begin{array}{l}68.25 \\
(6.51)\end{array}$ & $80.72(8.12)$ & $\begin{array}{l}12.74 \\
(5.56,19.38)\end{array}$ & $\begin{array}{l}3.79 \\
(18)\end{array}$ & $0.001^{\mathrm{a}}$ \\
\hline Compressive strength & 10 & $122.84(34.14)$ & $\begin{array}{l}272.73 \\
(42.64)\end{array}$ & $\begin{array}{l}149.89 \\
(113.60,186.18)\end{array}$ & $\begin{array}{l}8.68 \\
(18)\end{array}$ & $0.000^{\mathrm{a}}$ \\
\hline
\end{tabular}

Abbreviations: $\mathrm{Cl}$, confidence interval; $\mathrm{df}$, degrees of freedom; SD, standard deviation.

andependent $t$-test (significant at $p<0.05$ ).

Table 4 Comparison between the diameter $(\mu \mathrm{m})$ of raw kenaf fiber and treated kenaf fiber

\begin{tabular}{|l|l|l|l|}
\hline Sample of fibers & Range of diameter $(\mu \mathrm{m})$ & Average of diameter $(\mu \mathrm{m})$ & Standard deviation $(\mathrm{SD})$ \\
\hline Raw kenaf fibers & $6.65-16.53$ & 11.74 & 3.32 \\
\hline Treated kenaf fibers & $6.56-12.41$ & 10.30 & 2.05 \\
\hline
\end{tabular}

composite resin and Tetric $\mathrm{N}$ Flow (Ivoclar Vivadent, Liechtenstein) composite is shown in -Table 3.

\section{Diameter of Kenaf Fibers}

The diameter of a bundle of raw kenaf fibers ( - Fig. 1) was found to be larger than the treated kenaf fibers ( - Fig. 2), 81.90 and $66.97 \mu \mathrm{m}$, respectively. Comparison between the diameter of raw kenaf fiber and treated kenaf fiber is as shown in - Table 4.

\section{Average Length of Kenaf Fibers}

From - Fig. 3, it can be observed that the length of a single strand of treated kenaf fibers varied from 0.96 to $1.59 \mathrm{~mm}$. We found that the average length of kenaf fibers used to fabricate the kenaf-reinforced composite resin was $1.24 \mathrm{~mm}$.

\section{Assessment of Surface Topography}

Raw Kenaf Fibers and Treated Kenaf Fibers

Obvious impurities can be seen on the surface of the raw kenaf fibers ( - Fig. 1) whereas treated kenaf fibers appeared to have a cleaner and roughened surface with clear physical appearance (-Fig. 2). The raw kenaf fiber appeared as a bundle of fibers rather than single stranded as observed in the treated kenaf fibers.

Fractured Surface of Kenaf-Reinforced Composite Resin From SEM observation, numerous pulled out fibers as well as voids can be observed across the fractured surface of kenaf-reinforced composite resin (-Fig. 4). Despite a lot of pulled out fibers present, good adaptation was shown between the fiber-matrix interfaces with only minimal gap in between the two surfaces that varies from 0.15 to $0.23 \mu \mathrm{m}$ (-Figs. 5 and 6 ).

\section{Discussion}

Compressive properties are related to the flexural properties of composites as lower compressive strength will lead

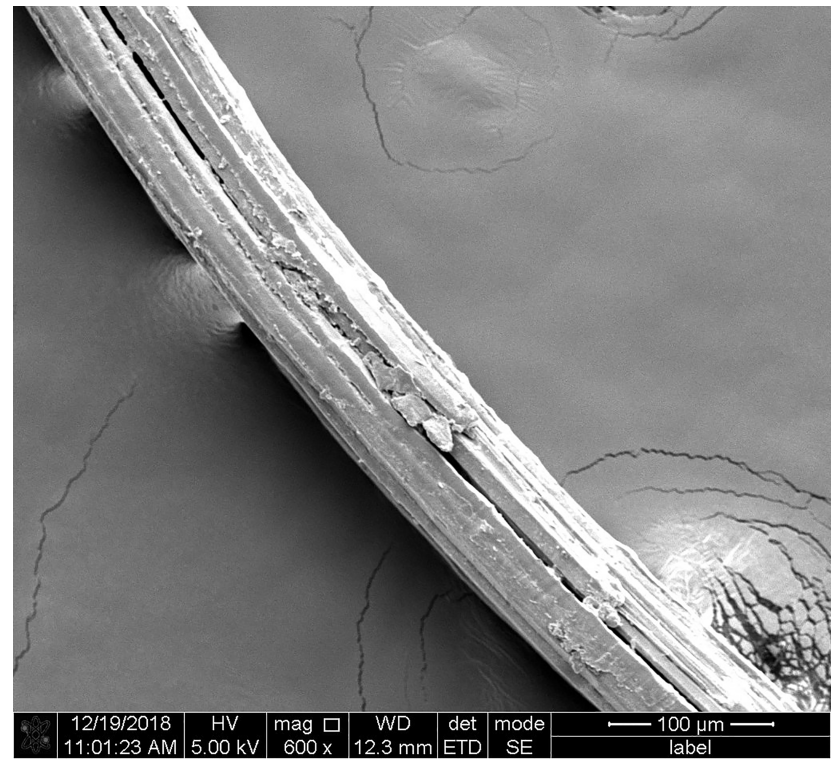

Fig. 1 Raw kenaf fibers.

to a high bending failure. ${ }^{12}$ Similar to that of flexural properties, the presence of porosity in the specimen that might have occurred due to the existence of voids could then prevent the stress applied to the specimen to be transferred effectively. This will result in lower flexural strength as the specimen was unable to maintain its integrity at the higher stress level. ${ }^{13}$ The lower compressive properties shown by the kenaf-reinforced composite resin might also be due to the low percentage of kenaf fiber loading. In a study done previously by Razavi et al, ${ }^{14}$ it was proven that higher fiber content had high ability to carry higher load. This statement was further supported by other study, Sharba et al ${ }^{12}$ which also observed that compressive strength of composite increased as more percentage of kenaf fiber was added.

In this study, we found that the flexural and compressive strength of Tetric N Flow (Ivoclar Vivadent, Liechtenstein) composite was higher as compared with the kenaf-reinforced composite resin. This finding could be explained by the fact 
that presence of void across the fractured surface of the kenaf-reinforced composite resin influenced the flexural and compressive strengths of the composite resin. Voids were pores that remained unoccupied in the composite resin that typically formed due to defects from the processing of the material..$^{15}$ Presence of void, even in small amount will influence the mechanical behavior of the composite particularly involving compressive strength ${ }^{16}$ Presence of voids caused the composite to have a higher porosity and Asumani et $\mathrm{al}^{17}$ reported that composites with less porous structure exhibited better mechanical properties. In this study, the materials were manually mixed that could contribute to the presence of void due to the air entrapment during the mixing process.

We observed that alkaline treatment caused reduction in diameter of the kenaf fibers. This result was supported by

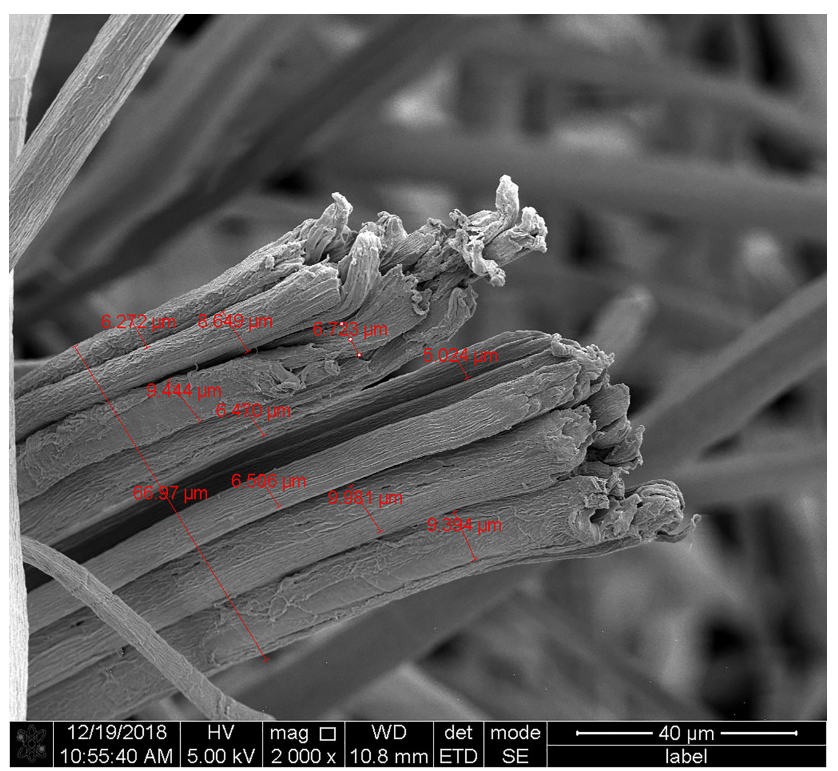

Fig. 2 Treated kenaf fibers.

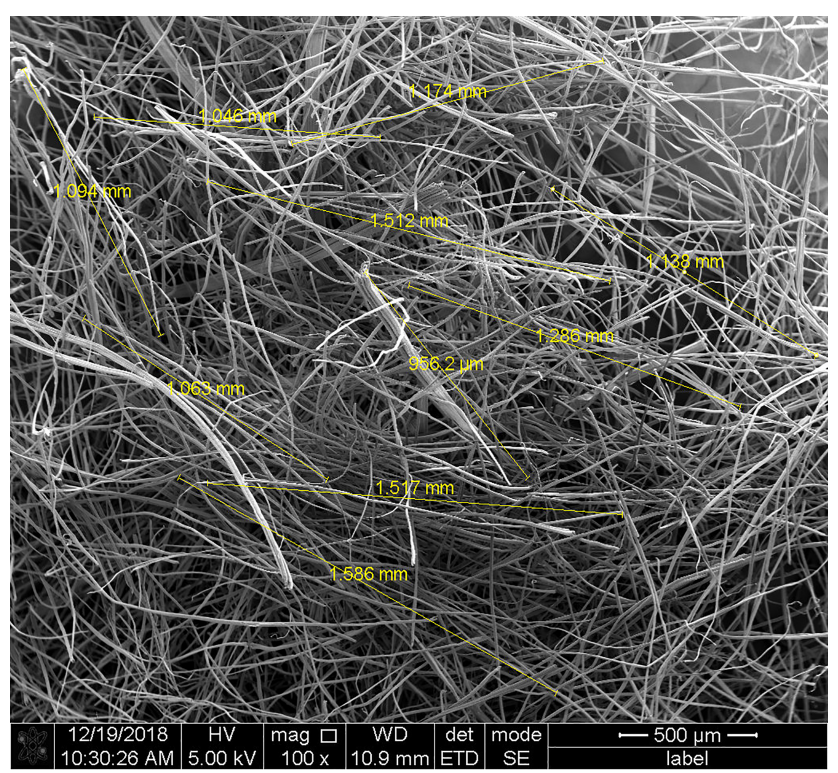

Fig. 3 Treated kenaf fiber at 100× magnifications.

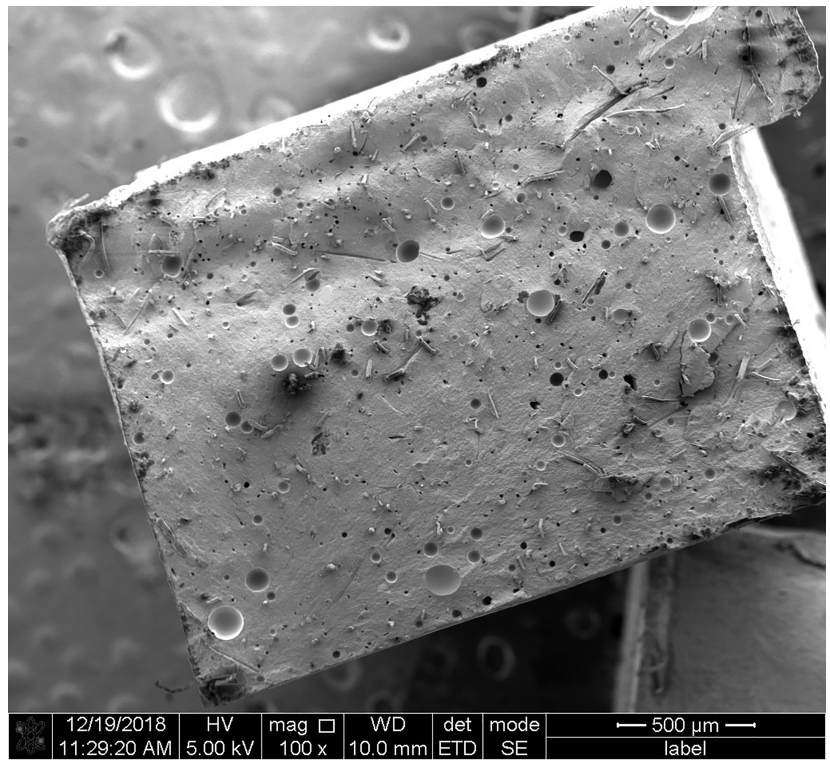

Fig. 4 Fractured surface of kenaf-reinforced composite resin.

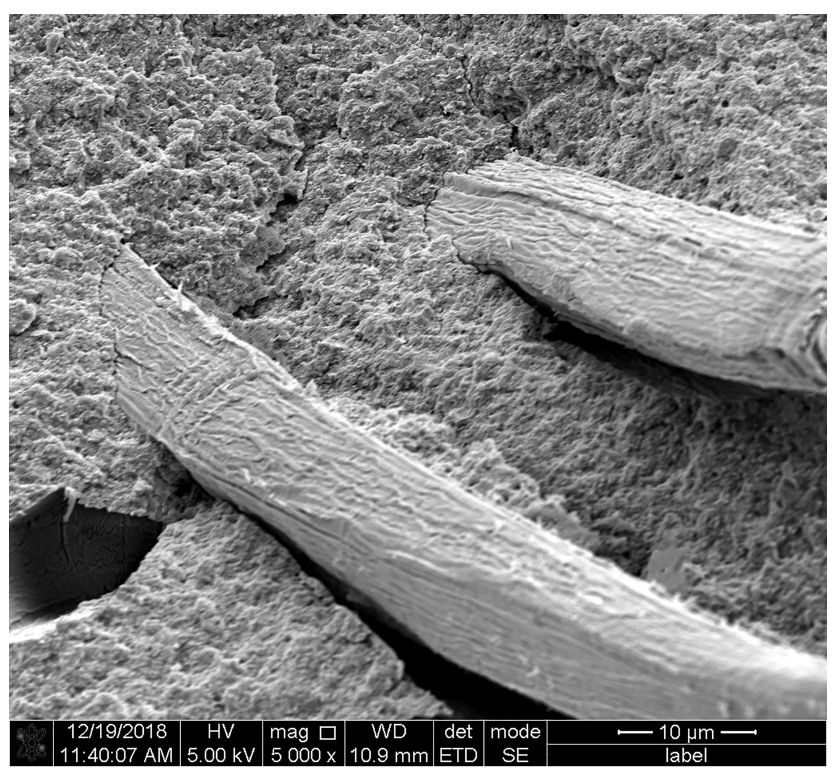

Fig. 5 Pulled out kenaf fibers presented on fractured surface.

previous study, Hashim et $\mathrm{a}^{18}$ who also reported decrement pattern of fibers diameter after treated with alkali solution. The authors claimed that the decrement pattern was the result of the alkali treatment that caused the degradation and delignification of fibers. Removal of noncellulosic materials resulted in finer diameter of the fibers. ${ }^{18,19}$ Under SEM observation, the impurities were seen on the surface of the raw kenaf fiber before the fibers were treated with alkali solution ( - Fig. 1) indicating the presence of discontinuous phase such as lignin and amorphous phase from the fiber. These impurities will affect the interfacial adhesion between kenaf fibers and matrix of resin which will further compromise the mechanical properties of the composite. ${ }^{20-22}$

These impurities cannot be seen on the surface of treated kenaf fibers as the surface treatment on the kenaf fibers using alkaline $(\mathrm{NaOH})$ helped to remove the impurities from 
the surface of fibers. The alkaline $(\mathrm{NaOH})$ treatment also was effective in removing hemicellulose and wax from the outer surface of kenaf fibers, which strengthened the interfacial bonding between kenaf fibers and matrix of composite resin. ${ }^{20-22}$

From the SEM observation, it was also revealed that fiber presented as a bundle of monofilament. Alkali $(\mathrm{NaOH})$ treatment removed the lignin which then resulted in the reduction of the fiber diameter ${ }^{18,19}$ and caused fibrillation of the fibers which referring to breakage of large fibers into smaller fibrils. The fibrillation helped to increase the fiber's aspect ratio (length/diameter ratio) and eliminate imperfections. $^{22}$ This improvement would later help in increasing the mechanical properties of the composite. The alkaline $(\mathrm{NaOH})$ treatment also increased the net cellulose content by removing all the noncellulosic phase from the fiber's surface and this would help to improve the structural stability to the fibers and composite as the cellulose content acted as structural bearing phase of the kenaf fiber. ${ }^{21}$

The alkaline $(\mathrm{NaOH})$ treatment resulted in good adaptation which was noted between the fibers and matrix of the resin presented by the minimal gap between the two surfaces (-Fig. 6). The good adaptation can be observed from the fractured surface of kenaf-reinforced composite resin and may be an indication of good interaction between the fiber and matrix ${ }^{23}$ as a result of alkaline $(\mathrm{NaOH})$ treatment ${ }^{20,24}$ that helped to remove discontinuous phase from the surface of the fibers. The effect of silane coupling agent helped to produce a stable covalent bond and further improved the fiber-matrix adhesion. In a moisture condition, silane coupling agent reduced the cellulose hydroxyl groups in the fiber-matrix interface by forming silanol. The silanol was able to react with the hydroxyl group from kenaf fibers and formed the stable covalent bond.?

The average length of the treated kenaf fibers to be used in composite resin was kept short as it was proved that flexural strength decreased when the fiber's length increased. ${ }^{23}$

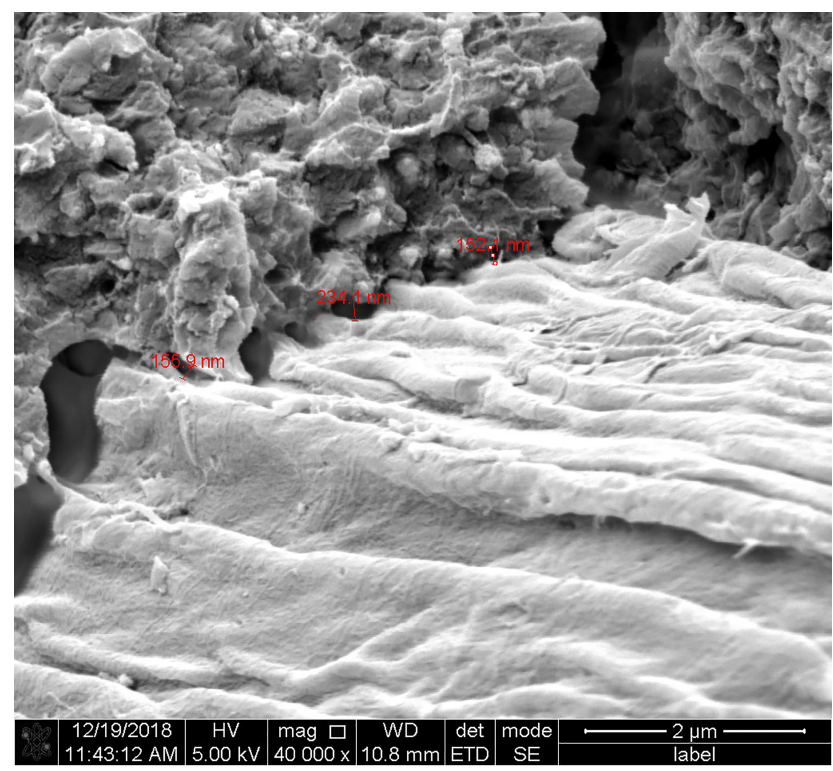

Fig. 6 Adaptation between kenaf fibers and matrix of resin.
According to Osman et $\mathrm{al}^{25}$ maximum flexural strength was observed when the fiber's length was around 1 to $6 \mathrm{~mm}$. Another previous study by Capela et $\mathrm{al}^{26}$ proved that dispersion of fibers in composite were only reasonable when the fibers' length was between 2 and $4 \mathrm{~mm}$ and as the fibers' length increased, poor dispersion of the fibers was reported with lack of interfacial adhesion due to fibers' agglomeration. Lack of fiber-matrix adhesion and more fiber content than matrix was observed when the length of the fibers was increased. ${ }^{27}$

Despite some adaptation of matrix to the fiber, we observed that numerous pulled out fibers across the fractured surface of kenaf-reinforced composite resin along with numerous voids and these led to lower flexural strength of the kenaf-reinforced composite resin. The observed pulled out kenaf fibers could be related to poor fiber-matrix adhe$\operatorname{sion}^{12}$ and it was related to load transfer mechanism from matrix to fiber. The pulled out kenaf fibers was explained by the fact that during loading of force, fiber-matrix interfacial bond strength was exceeded before failure strength of the composite resin was obtained. ${ }^{28,29}$ Akhtar et al ${ }^{20}$ also claimed that pulled out kenaf fibers from polypropylene matrix proved that the interfacial bonding between kenaf fibers and matrix was inadequate. This may be due to insufficient surface treatment on the kenaf fibers.

In conclusion, the flexural and compressive strength of kenaf incorporated composite were significantly lower than the Tetric N Flow (Ivoclar Vivadent, Liechtenstein) composite resin. A good adaptation between the fiber-matrix interfaces could be attributed to the alkaline treatment that was done on the kenaf fibers and the effect of silane coupling agent. The average length and diameter of kenaf fibers were reasonable to be dispersed in the composite. However, pulled out kenaf fibers indicated a poor fiber-matrix adhesion, and thus, more treatment need to be done to further improvise the fiber-matrix adhesion.

\section{Funding}

This research project was funded by the Ministry of Education (Malaysia) under Fundamental Research Grant Scheme (FRGS) (203/PPSG/6171207).

\section{Presentation at a Meeting}

1. Organization: 16th Students' Scientific Conference; Place: School of Dental Sciences, Universiti Sains Malaysia, Kota Bharu, Kelantan, Malaysia; Date: February 21, 2019.

2. Organization: 18th Annual Scientific Meeting of IADR Malaysian Section; Place: Kuala Lumpur; Date: March 30, 2019.

3. Organization: 11th Dental Students' Scientific Conference; Place: Kuala Lumpur; Date: April 27, 2019.

\section{Conflict of Interest}

None declared.

\section{Acknowledgments}

We would like to express our deepest gratitude and appreciation to Mr. Yusoff Soon Abdullah for his guidance 
and effort in helping us to complete this research. We also would like to thank the management, School of Dental Sciences, Universiti Sains Malaysia, for giving us permission to use the facilities to complete this project.

\section{References}

1 Alshali RZ, Salim NA, Sung R, Satterthwaite JD, Silikas N. Qualitative and quantitative characterization of monomers of uncured bulk-fill and conventional resin-composites using liquid chromatography/mass spectrometry. Dent Mater 2015;31(6):711-720

2 Huang Q Garoushi S, Lin Z, et al. Properties of discontinuous S2-glass fiber-particulate-reinforced resin composites with two different fiber length distributions. J Prosthodont Res 2017;61(4):471-479

3 Nishino T, Hirao K, Kotera M, Nakamae K, Inagaki $\mathrm{H}$. Kenaf reinforced biodegradable composite. Compos Sci Technol 2003;63:1281-1286

4 Wambua P, Verpoest J. Natural fibers: can they replace glass in fiber reinforced plastics? Compos Sci Technol 2003;63:1259-1264

5 Jawaid M,Abdul Khalil HPS.Cellulosic/synthetic fiber reinforced polymer hybrid composites. Carbohydr Polym 2011;86:1-18

6 Saba N, Paridah MT, Jawaid M. Mechanical properties of kenaf fiber reinforced polymer composite: A review. Constr Build Mater 2015;76:87-96

7 Akil HM, Omar MF, Mazuki AA, Safiee S, Ishak ZAM, Abu Bakar A. Kenaf fiber reinforced composites: A review. Mater Des 2011;32:4107-4121

8 Mohd Edeerozey AM, Md Akil H, Azhar BM, Zainal Ariffin I. Chemical modification of kenaf fibers. Mater Lett 2007;61:2023-2025

9 Mahjoub R, Mohamad Yatim J, Mohd Sam AR, Hashemi SH. Tensile properties of kenaf fiber due to various conditions of chemical fiber surface modifications. Constr Build Mater 2014;55:103-113

10 Shin HK, Jeun JP, Kim HB, Kang PH. Isolation of cellulose fibers from kenaf using electron beam. Radiat Phys Chem 2012;81:936-940

11 Kargarzadeh H, Ahmad I, Abdullah I, Dufresne A, Zainudin SY, Sheltami RM. Effects of hydrolysis conditions on the morphology, crystallinity, and thermal stability of cellulose nanocrystals extracted from kenaf bast fibers. Cellulose 2012;19:855-866

12 Sharba MJ, Leman Z, Sultan MTH, Ishak MR, Azmah Hanim MA. Tensile and compressive properties of woven kenaf/glass sandwich hybrid composites. Int J Polym Sci 2016;2016:1-6

13 Bajuri F, Mazlana N, Ishak MR, Imatomi J. Flexural and compressive properties of hybrid kenaf/silica nanoparticles in epoxy composite. Procedia Chem 2016;19:955-960

14 Razavi M, Babatunde OE, Mohamad Yatim J, Razavi M, Mizal Azzmi N. Compressive properties of kenaf/ vinylester composite with different fiber volume. Adv Sci Lett 2018;24:3894-3897

15 Badri M,Sugiman, Aguswandi,JayadiJ.SEM observation on fracture surface of coconut fibers reinforced polyester composite. J Ocean Mechanical Aerospace-Sci Engineering 2017;40:22-27

16 Mehdikhani M, Gorbatikh L, Verpoest I, Lomov SV. Voids in fiber-reinforced polymer composites: a review on their formation, characteristics, and effects on mechanical performance. J Compos Mater 2019;53:1579-1669

17 Asumani OML, Reid RG, Paskaramoorthy R. The effects of alkali-silane treatment on the tensile and flexural properties of short fiber non-woven kenaf reinforced polypropylene composites. Compos, Part A Appl Sci Manuf 2012;43:1431-1440

18 Hashim MY, Mohd Amin A, Faizan Marwah OM, et al. The effect of alkali treatment under various conditions on physical properties of kenaf fiber. J Phys Conf Ser 2017;914:1-15

19 Gomes A, Goda K, Ohgi J. Effects of alkali treatment to reinforcement on tensile properties of curaua fiber green composites. JSME Int J Ser A 2004;47:541-546

20 Akhtar MN, Sulong AB, Radzi MKF, et al. Influence of alkaline treatment and fiber loading on the physical and mechanical properties of kenaf/polypropylene composites for variety of applications. Prog Nat Sci-Mater 2016;26:657-664

21 Mohan TP, Kanny K. Mechanical properties and failure analysis of short kenaf fiber reinforced composites processed by resin casting and vacuum infusion methods. Polym Polymer Compos 2018;26:189-204

22 Hassan A, Mohd Isa MR, Mohd Ishak ZA, Ishak NA, Rahman NA, Md Salleh F. Characterization of sodium hydroxide-treated kenaf fibers for biodegradable composite application. High Perform Polym 2018;30:890-899

23 Morais JAD, Gadioli R, De Paoli MA. Curaua fiber reinforced high-density polyethylene composites: Effect of impact modifier and fiber loading. Polímeros 2016;26:115-122

24 Nirmal U, Lau STW, Hashim J. Interfacial adhesion characteristics of kenaf fibers subjected to different polymer matrices and fiber treatments. J Compos 2014;2014:1-12

25 Osman E, Vakhguelt A, Sbarski I, Mutasher S. Mechanical properties of kenaf - unsaturated polyester composites: effect of fiber treatment and fiber length. Adv Mat Res 2011;311-313:260-271

26 Capela C, Oliveira SE, Pestanaa J, Ferreira JAM. Effect of fiber length on the mechanical properties of high dosage carbon reinforced. Procedia Struct Integr 2017;5:539-546

27 Venkateshwaran N, Elayaperumal A, Jagatheeshwaran MS. Effect of fiber length and fiber content on mechanical properties of banana fiber/epoxy composite. J Reinf Plast Compos 2011;30:1621-1627

28 Okoli OI, Smith GF. Failure modes of fiber reinforced composites: the effects of strain rate and fiber content. J Mater Sci 1998;33:5415-5422

29 Tan Y, Wang X, Wu D. Preparation, microstructures, and properties of long-glass-fiber-reinforced thermoplastic composites based on polycarbonate/poly (butylene terephthalate) alloys. J Reinf Plast Compos 2015;34:1804-1820 